\title{
Planar UWB Monopole Antenna with Tri-Band Rejection Characteristics at 3.5/5.5/8 GHz
}

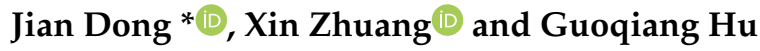 \\ School of Information Science and Engineering, Central South University, Changsha 410083, China; \\ zhuangxin@csu.edu.cn (X.Z.); hgqcool@163.com (G.H.) \\ * Correspondence: dongjian@csu.edu.cn
}

Received: 3 November 2018; Accepted: 25 December 2018; Published: 29 December 2018

\begin{abstract}
A triple band-notched ultrawide band (UWB) antenna is presented to avoid the interference of services working in the UWB band, such as WLAN, WiMAX and X-band satellite systems. The arc $\mathrm{H}$-shaped slot on the radiating patch creates a low frequency notched band, while the other two band-notched bands are formed by cutting narrow slots on the ground plane. The presented antenna can operate on the ultrawide band efficiently and inhibit interference from three different kinds of narrow band communication systems. The simulation and measurement results show that the antenna has excellent band-notched function on the rejectband and almost omnidirectional radiation pattern on the passband.
\end{abstract}

Keywords: ultrawide band (UWB) antenna; triple band-notched; slots; planar monopole antenna

\section{Introduction}

Recently, ultra-wideband (UWB) systems have attracted widespread attention. Compared with the traditional wireless system, the ultra-wideband system has some advantages such as strong anti-multipath effect ability, strong anti-interference ability, insensitivity to channel fading, low cost and low system complexity [1]. Therefore, the UWB system is widely used, such as: multiple-input multiple-output (MIMO)communication systems [2,3], medical technologies [4,5], disaster rescue communication environments [6], plant root imaging [7], wireless vital signs monitoring [8], and so on.

As a significant component of the UWB system, UWB antennas have been extensively studied in academia and industry. In particular, planar UWB antennas have attracted great attention because of their low cost, small size and ease of manufacture. However, within the specified UWB frequency range, there are some other narrowband communication systems, such as WLAN $(5.15-5.825 \mathrm{GHz})$, WiMAX (3.3-3.7 GHz), and X-band satellite applications operating near $8 \mathrm{GHz}$, which may cause electromagnetic interference to the UWB applications. Therefore, in order to mitigate potential interference, it is essential for the UWB antenna to have band-notched function at these service frequencies [9,10]. In recent years, a variety of planar UWB slot antennas with band-notched function have been presented, such as embedding a slender slot in a patch antenna [11], combining a C-shaped parasitic strip with the circular slot antenna [12], and embedding a convex-shaped patch by an elliptic slot and a rectangular slot [13]. However, these antennas have only one notched band. In [14], a UWB antenna was proposed in which two C-shaped slots were cut in the radiation patch to achieve dual band-notched function. In [15], the dual band-notched function was achieved by cutting one quasi-complementary split-ring resonator in the feed line. In [16], the dual band-notched function was realized by cutting two L-shaped slots and an E-shaped slot with variable size on the radiation patch. In [17], by cutting an inverted G-shaped slot on the ground plane and elliptical slot on the modified circular patch, a 3.5/5.5 GHz dual band-notched UWB antenna was presented. 
However, in these UWB antennas, most of them do not exceed two notched bands. There are fewer designs with three notched bands, which indicating that these dual band-notched UWB antennas may still be subject to interference from other narrow bands. In [18], a circular antenna with triple band-notched function at $2.45,5.45$, and $8 \mathrm{GHz}$ was presented by using an inverted L-shaped slot and a ring on the circular patch. In [19], a UWB printed planar antenna with tri-band notched functions was presented. A notched band at 5.3-6.2 GHz was achieved by using a U-shaped slot defected ground structure. By cutting the $\mathrm{H}$-shaped slot on the radiation patch, a notched band at $3.4-4.15 \mathrm{GHz}$ for WiMAX and a notched band at $6.8-7.7 \mathrm{GHz}$ for some X-band satellite communication systems were achieved. In [20], an antenna with band-notched function at 3.5, 4.5, 5.25, and 5.65 GHz was presented by using a complementary split ring resonator (CSRR) on a semicircular patch. In [21], by cutting four rectangular complementary split ring resonators (RCSRR) on the radiating patch and two rectangular open-loop resonators placed near the feedline, a smallest form factor UWB antenna with band-notched function at 3.5, 4.5, 5.25, 5.7 and $8.2 \mathrm{GHz}$ was presented. In [22], by cutting two elliptic single complementary split ring resonators (ESCSRRs) on the radiating patch and placing two rectangular split-ring resonators near the feedline-patch junction of the antenna, a low profile microstrip fed compact UWB antenna with band-notched function at 3.54, 5.73 and $8.56 \mathrm{GHz}$ was presented. In [23], an antenna with band-notched function at 3.55, 5.5, 7.8 GHz was presented by using a pair of modified capacitance loaded loop (MCLL) resonators. In [24], by cutting C-shaped slot and arc shaped slot on the radiating patch and using an annular strip above the radiating element, an antenna with band-notched function at $3.45,5.5$ and $7.4 \mathrm{GHz}$ was presented. In [25], a compact UWB antenna with band-notched function at $3.5,5.4$ and $8.4 \mathrm{GHz}$ was presented by cutting three square slots into the microstrip feedline. Although three notched bands were obtained, the completeness of the notched-band coverage was sacrificed in these designs. For instance, the antenna in [18] did not generate a notched band for WiMAX (3.3-3.7 GHz). The rejectband coverage for WLAN $(5.15-5.825 \mathrm{GHz})$ was not complete in [19]. The antenna in [20,24] did not generate a notched band for X-band satellite applications operating near $8 \mathrm{GHz}$. In [21], almost no passband was available after the highest frequency notched band. The size of antenna in [22] was too large. In [23,25], the rejectband coverage for WiMAX was not complete.

In this paper, a UWB antenna with a triple band-notched function is presented by cutting an arc H-shaped slot on the circular radiating patch and etching narrow slots on the ground plane. The presented antenna can operate within an ultrawide band from $3.1 \mathrm{GHz}$ to about $10 \mathrm{GHz}$. At the same time, the antenna can completely reject three notched bands of $2.59-4.01 \mathrm{GHz}, 4.73-6.11 \mathrm{GHz}$, 7.68-8.40 GHz. Thus, avoiding the interference from WLAN, WiMAX, and X-band satellite systems. Specific details about the antenna design, as well as the results of the simulations and measurements, are described and discussed below.

\section{Antenna Design}

Figure 1 shows the structure of the presented planar UWB monopole antenna with triple band-notched function. The antenna was manufactured on a FR-4 substrate. The thickness of the substrate was $1.6 \mathrm{~mm}$. The antenna consists of a planar circular disc monopole with an arc H-shaped slot and is fed by a $50 \mathrm{ohm}$ microstrip line. Compared to straight-shaped H-shaped slot [19], the arc $\mathrm{H}$-shaped slot can provide more degrees of freedom (such as $\alpha, \mathrm{L} 1, \mathrm{~W} 2)$ for tuning the center frequency of the desired rejectband. The ground plane was reshaped as T-shaped defected ground structure with two narrow L-shaped slots on the top and a narrow slot on the bottom. The top corners were removed to improve the impedance bandwidth and reduce the return loss. Note that, the general length of the L-shaped slots, $l$, can be approximately calculated by:

$$
f_{\text {notch }}=\frac{c}{4 l \sqrt{\varepsilon_{e}}} .
$$


where $f_{\text {notch }}$ is the center frequency of the stopband, $c$ is the light speed, $\varepsilon_{e}=\left(\varepsilon_{r}+1\right) / 2$ is the effective permittivity, $\varepsilon_{r}$ is the relative permittivity. Assume the center frequency of the WLAN working frequency band is $5.6 \mathrm{GHz}$ and the total length of L-shaped slot is about $7.9 \mathrm{~mm}$. It is calculated that for a center frequency of WLAN of $5.6 \mathrm{GHz}$, the total length $l$ of the L-shaped slot is about $7.9 \mathrm{~mm}$; for the center frequency of the X-band of $8.1 \mathrm{GHz}$, the length of the narrow slot on the bottom of the ground plane is about $5.6 \mathrm{~mm}$. The final UWB antenna design achieved dual band-notched function by adjusting the width, length and slot size of the radiating patch and the defected ground structure. Table 1 shows the optimized values of the parameters in the presented antenna. The specific parameters are studied in the next section. Figure 2 illustrates the return loss of the presented antenna structure. As shown in from Figure 2 (curve (i)), a stopband at low frequency can be excited by cutting an arc $\mathrm{H}$-shaped slot on the radiation patch. And curve (ii) illustrates that two stopbands (one at the same low frequency and the other at medium frequency) are excited by cutting the arc $\mathrm{H}$-shaped slot on the radiating patch and two narrow L-shaped slots on the ground plane. In addition, curve (iii) illustrates that another high frequency stopband is excited due to the narrow slot on the bottom ground plane.

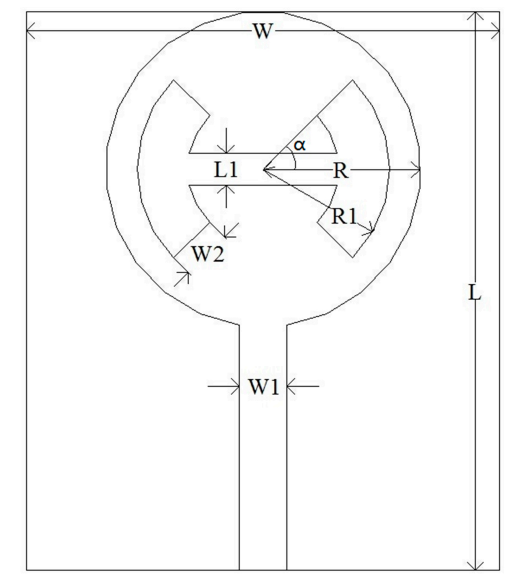

(a)

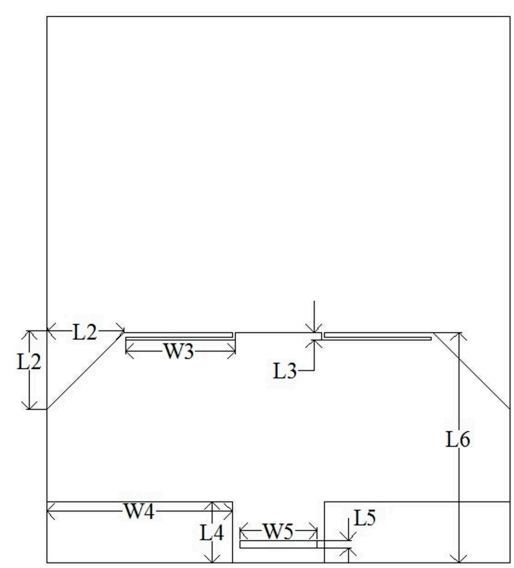

(b)

Figure 1. Schematic configuration of the proposed tri-band-notched antenna: (a) Patch; (b) Ground Plane.

Table 1. Design Parameters of the Proposed UWB Antenna ( $\mathrm{mm})$.

\begin{tabular}{cccccccc}
\hline $\boldsymbol{W}$ & $\boldsymbol{L}$ & $\boldsymbol{\alpha}$ & $\boldsymbol{R}$ & $\boldsymbol{R}_{\mathbf{1}}$ & $\boldsymbol{W}_{\mathbf{1}}$ & $\boldsymbol{L}_{\mathbf{1}}$ & $\boldsymbol{W}_{\mathbf{2}}$ \\
\hline 30 & 35.5 & $\pi / 4$ & 10 & 8 & 3 & 2 & 3.2 \\
\hline $\boldsymbol{L}_{\mathbf{2}}$ & $\boldsymbol{W}_{\mathbf{3}}$ & $\boldsymbol{L}_{\mathbf{3}}$ & $\boldsymbol{W}_{\mathbf{4}}$ & $\boldsymbol{L}_{\mathbf{4}}$ & $\boldsymbol{W}_{\mathbf{5}}$ & $\boldsymbol{L}_{\mathbf{5}}$ & $\boldsymbol{L}_{\mathbf{6}}$ \\
\hline 5 & 7.3 & 0.5 & 12 & 4 & 5.5 & 0.7 & 15 \\
\hline
\end{tabular}

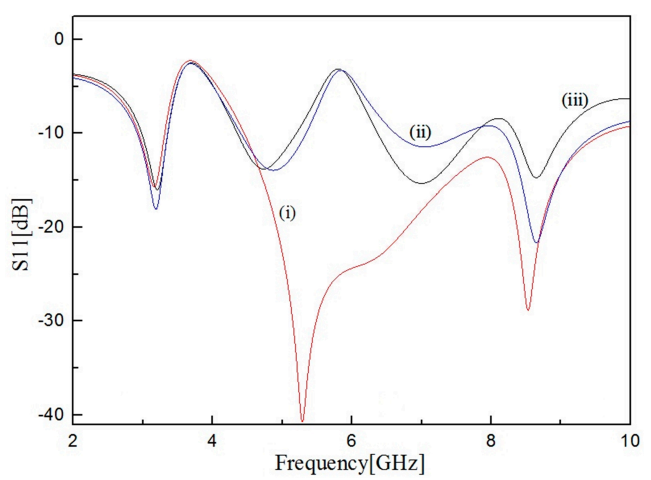

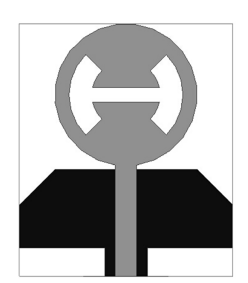

(i)

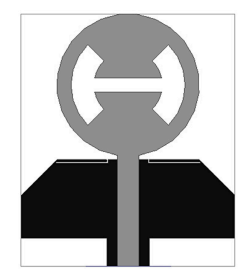

(ii)

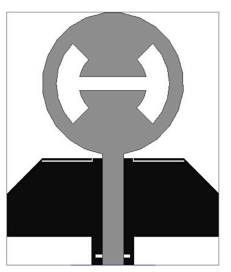

(iii)

(b)

(a)

Figure 2. Stepwise evolution of the antenna and corresponding simulated return loss: (a) Simulated return loss against frequency for the various configurations; (b) structure evolution of antenna. 
Therefore, by cutting the arc $\mathrm{H}$-shaped slot on the radiating patch and three narrow slots on the ground plane, three stopband rejections were formed. And their center frequencies were $3.8 \mathrm{GHz}$, $5.6 \mathrm{GHz}$ and $8.1 \mathrm{GHz}$, respectively.

To further explain the three notched band, Figure 3 shows the distribution of current on the antenna surface at three frequencies of $3.8 \mathrm{GHz}, 5.6 \mathrm{GHz}$ and $8.1 \mathrm{GHz}$. In Figure 3a, it can be seen that at $3.8 \mathrm{GHz}$, the current was distributed over the edges of the curved $\mathrm{H}$-shaped slot on the radiation patch. In Figure $3 b$, it can be observed that at $5.6 \mathrm{GHz}$, the current was distributed on the edge of the L-slot on the ground plane. Figure $3 c$ reveals that the third stopband was excited mainly due to rectangular slot under the microstrip of the radiating patch.

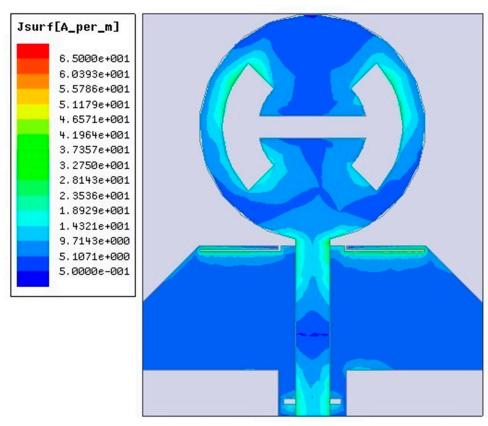

(a)

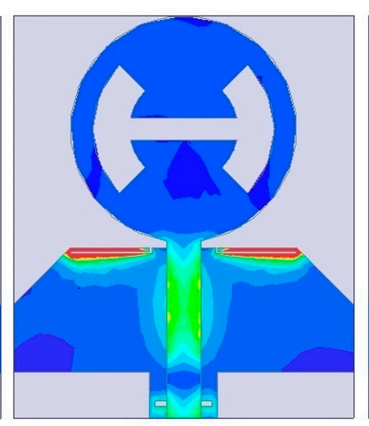

(b)

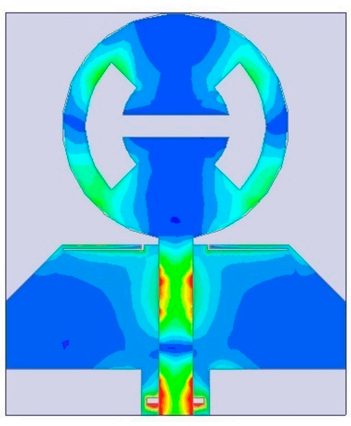

(c)

Figure 3. Simulated surface current distributions at (a) $3.8 \mathrm{GHz},(\mathbf{b}) 5.6 \mathrm{GHz}$, and (c) $8.1 \mathrm{GHz}$.

\section{Parametric Study}

The parameters on the presented triple band-notched antenna were studied by Ansoft HFSS to investigate how they affected the performance of this antenna.

\subsection{Variation of Patch Parameters}

The size of the patch slot is critical to the first notched-band. Figure 4 shows the effect of the parameter $\alpha$ changing from 30 degrees to 60 degrees on the simulated return loss, and other parameters are the same as those listed in Table 1. It can be seen from Figure 4 that when $\alpha$ increased from 30 degrees to 60 degrees, the lower notched band moved towards the low frequency. In addition, it was found that $\alpha$ slightly affected the third notched-band, and hardly affected the middle notched-band. Thus, Figure 4 indicates that the optimum value of $\alpha$ is 45 degrees. Another important parameter R1 is studied and shown in Figure 5. It can be seen from the simulation results that the low notched-band moved to the low frequency when the value of R1 increased from $7.0 \mathrm{~mm}$ to $9.0 \mathrm{~mm}$, and it had little effect on the middle notched-band and third notched-band. Therefore, the value of R1 was chosen to be $8.0 \mathrm{~mm}$, moving the low notched-band to $3.8 \mathrm{GHz}$.

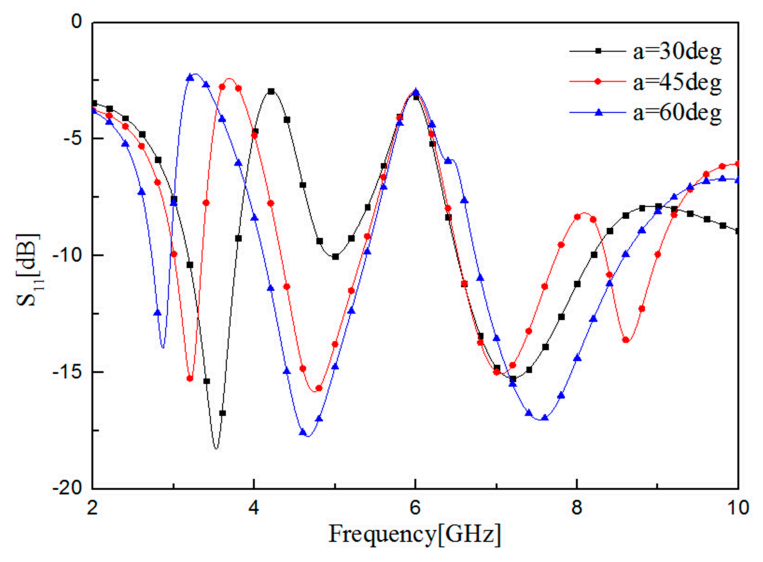

Figure 4. Effect of parameter $\alpha$ on the simulated return loss. 


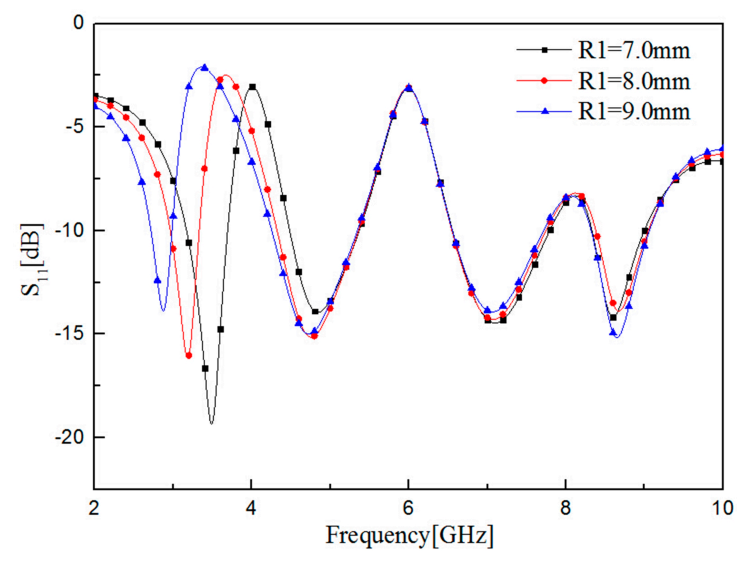

Figure 5. Effect of parameter $R 1$ on the simulated return loss.

\subsection{Variation of Ground Parameters}

The effect of changing parameter W3 on the simulated return loss is shown in Figure 6. The middle notched-band shifted towards lower frequency with the increasing of W3 and at the value of $7.3 \mathrm{~mm}$, the desired middle stopband was obtained. Figure 7 shows how the parameter of the slot on the ground plane affected the performance of antenna. It can be found that the performance of the third notched-band mainly depended on the parameter L5, and L5 $=0.7 \mathrm{~mm}$ was chosen as an optimum value.

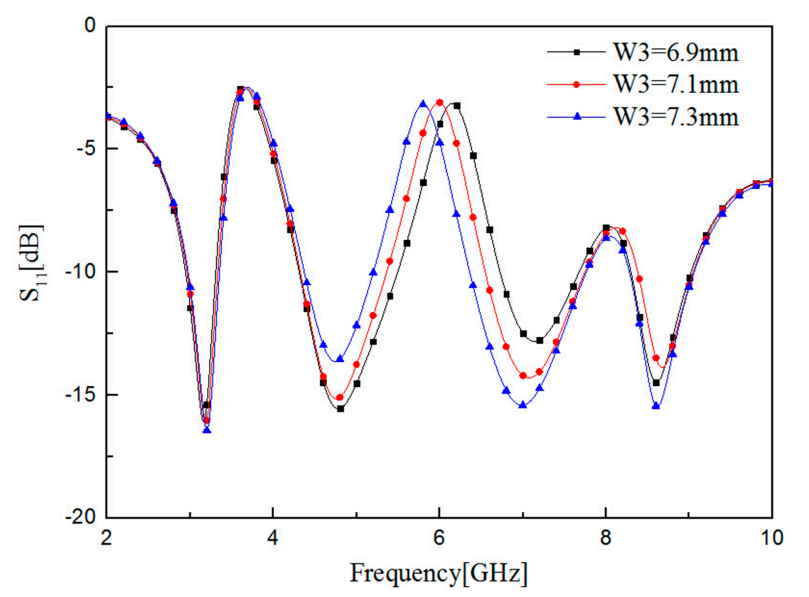

Figure 6. Effect of parameter $W 3$ on the simulated return loss.

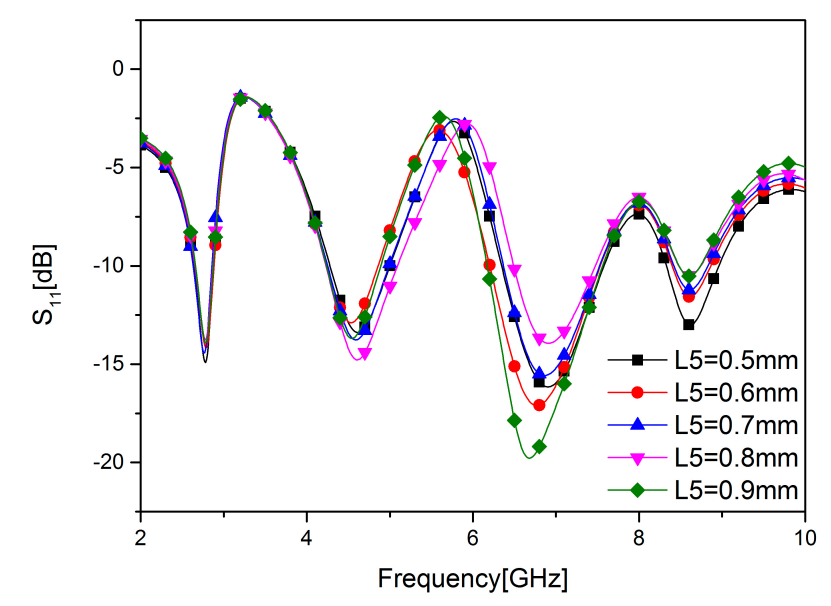

Figure 7. Effect of parameter $L 5$ on the simulated return loss. 


\section{Results and Discussion}

To verify the proposed design, the antenna was manufactured on a FR-4 substrate. The dimensions of the substrate was $35.5 \mathrm{~mm} \times 30 \mathrm{~mm} \times 1.6 \mathrm{~mm}$. The photo of the fabricated antenna is shown in Figure 8 . The return loss of the antenna was measured by using an Agilent N5230A vector network analyzer. The measurement and simulation results of the return loss are shown in Figure 9, which shows a good agreement between the simulation results and the measurement results. The slight deviation may be due to fabrication imperfection or SMA connector error. The results show that the presented design had triple band-notched function, i.e., band I from 2.59-4.01 GHz, band II from 4.73-6.11 GHz, and band III from 7.68-8.40 GHz, which obviously avoid WiMAX, WLAN interference, and X-band satellite system.

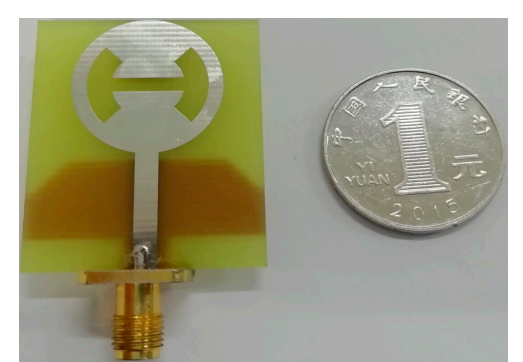

(a)

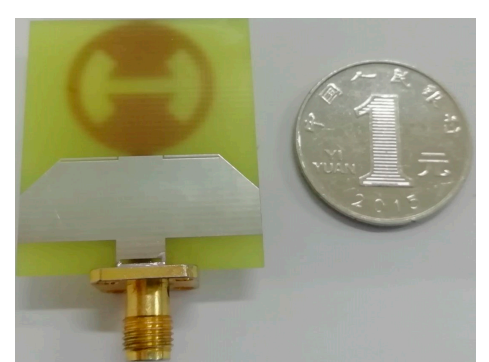

(b)

Figure 8. Photo of the fabricated antenna: (a) front view; (b) back view.

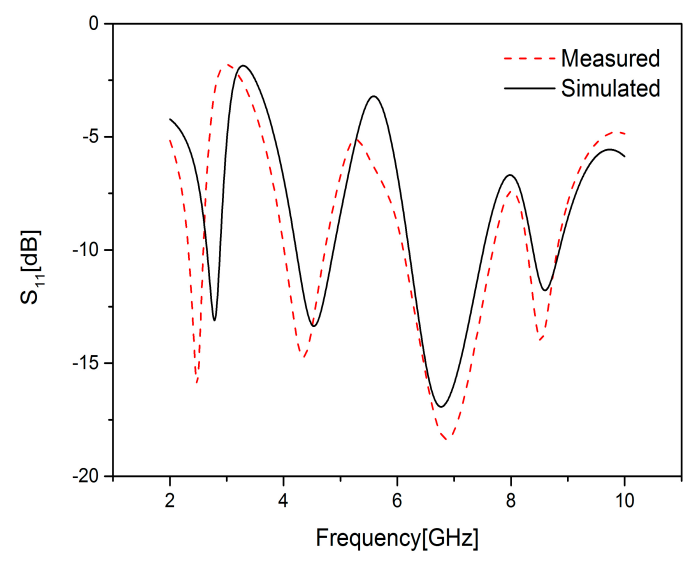

Figure 9. Simulated and measured results of the return loss of the proposed antenna.

The proposed antenna can be equivalent to the circuit model shown in Figure 10, which contains three parallel RLC resonant loops. When the circuit was operating, the first RLC parallel resonant loop resonated at $3.5 \mathrm{GHz}$, corresponding to the $\mathrm{H}$-shaped slot on the radiating patch; the second RLC parallel resonant loop resonated at $5.6 \mathrm{GHz}$, corresponding to the L-shaped slot on the ground plane; the third RLC parallel resonant loop resonated at $8.1 \mathrm{GHz}$, corresponding to the rectangular slot below the microstrip line. When the circuit operates at the notched band frequency, the value of the input resistance of the circuit becomes maximum. The RLC parameters' value can be given by the following formulas [26]:

$$
\begin{gathered}
Q_{0}=\frac{f}{B W} \\
Q_{0}=2 \pi f_{0} R C \\
f_{0}=\frac{1}{2 \pi \sqrt{L C}}
\end{gathered}
$$

where $f_{0}$ is the resonant frequency, $Q_{0}$ is the quality factor, BW is the RLC bandwidth, $R$ is the resistance value, $C$ is the capacitance value, and $L$ is the inductance value in the RLC parallel resonant loop. 
Firstly, we obtained the curve of the input impedance with the frequency as shown in Figure 11. The resistance values of the three RLC parallel resonant loops resonance were obtained from the peak values of the real component curve. Then, we calculated the quality factors by Formula (2). Finally, we calculated other parameter values by Formula (3) and Formula (4). Table 2 shows the specific parameter values of the RLC equivalent circuit. The equivalent circuit was simulated by ADS 2017. The return loss of the equivalent circuit was compared with measurement and simulation results of the designed antenna in Figure 12, which showed the good consistency between the equivalent circuit and the designed antenna.

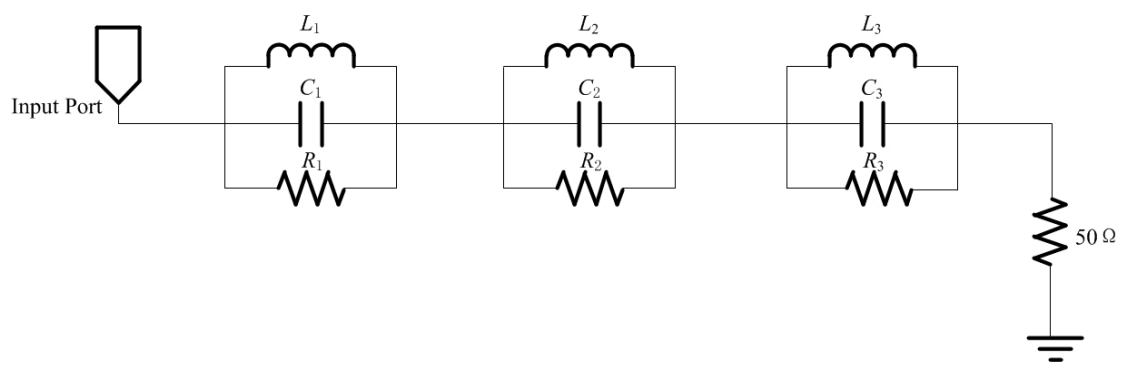

Figure 10. Schematic of the equivalent RLC resonant circuit model of the proposed antenna.

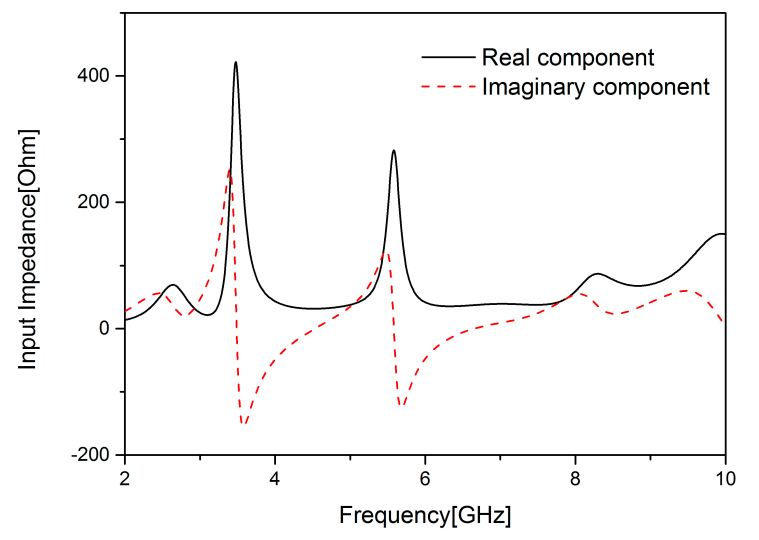

Figure 11. Input Impedance results of the proposed antenna.

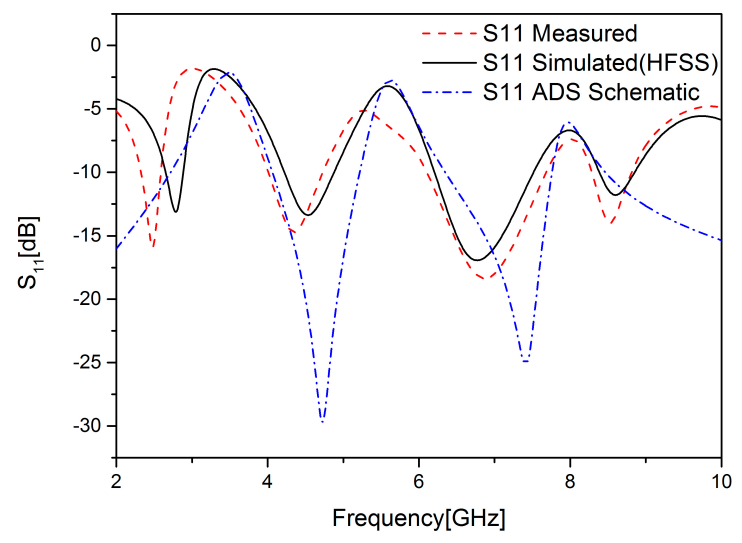

Figure 12. The comparison of equivalent circuit's return loss with simulated and measured results of return loss of the proposed antenna.

Figure 13 shows the variation of realized gain and antenna efficiency with frequency. It can be observed that the realized gain and antenna efficiency decrease significantly at the three stopbands. Figure $14 \mathrm{a}-\mathrm{d}$ shows the 2-D far-field simulation radiation patterns in the yz-plane and xz-plane at sampling frequencies of $2.5 \mathrm{GHz}, 4.5 \mathrm{GHz}, 7.0 \mathrm{GHz}$, and $8.6 \mathrm{GHz}$ respectively. In these figures, it was found that the omnidirectional radiation characteristics were good. The results show that 
the presented antenna performed well in four different passbands and meet the requirements of UWB communications.

Table 2. Calculated equivalent circuit parameter values.

\begin{tabular}{cccccc}
\hline Circuit & BW $(\mathbf{M H z})$ & $Q_{0}$ & $\boldsymbol{R}(\boldsymbol{\Omega})$ & $\boldsymbol{L}(\mathbf{p H})$ & $\boldsymbol{C}(\mathbf{p F})$ \\
\hline 1 & 144 & 24.3 & 357 & 664.51 & 3.11 \\
\hline 2 & 153 & 36.6 & 268 & 208.17 & 3.88 \\
\hline 3 & 251 & 32.4 & 89 & 53.99 & 7.51 \\
\hline
\end{tabular}

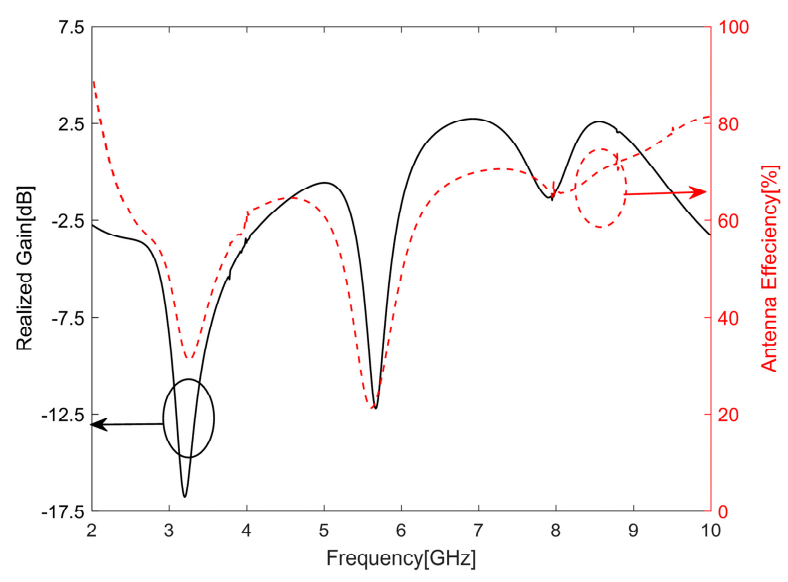

Figure 13. Realized gain and antenna efficiency of the proposed tri-band-notched UWB antenna.

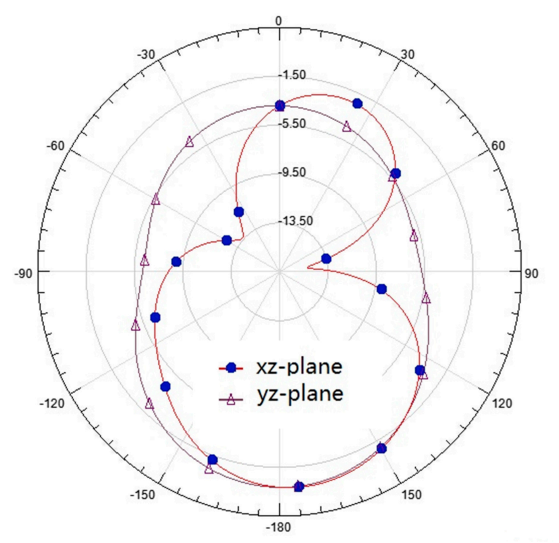

(a)

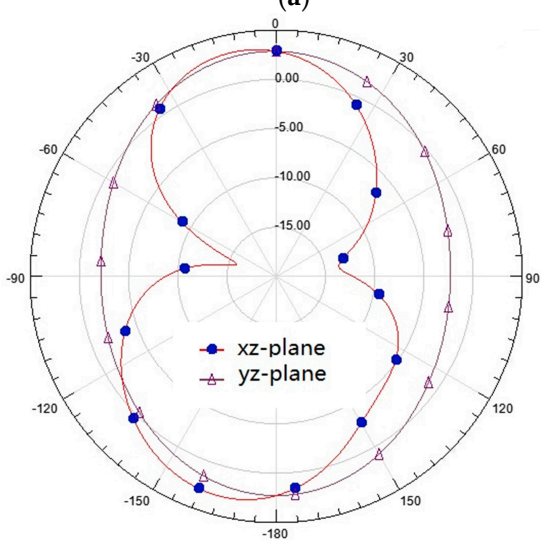

(c)

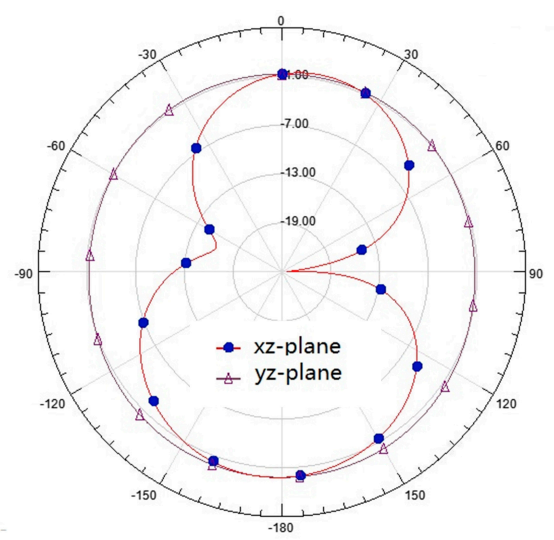

(b)

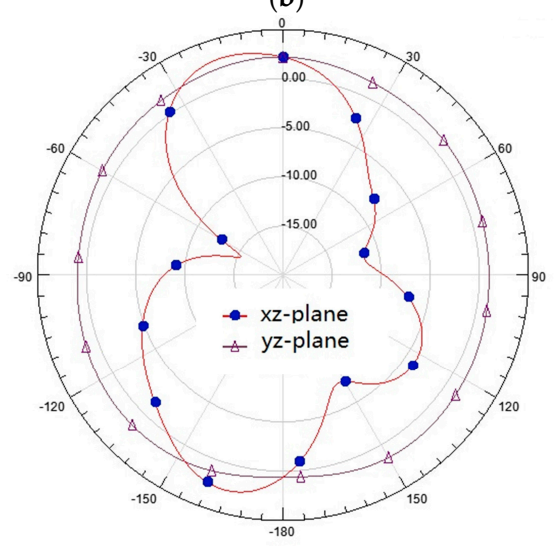

(d)

Figure 14. Simulation radiation patterns at (a) $2.5 \mathrm{GHz}$, (b) $4.5 \mathrm{GHz}$, (c) $7.0 \mathrm{GHz}$, and (d) $8.6 \mathrm{GHz}$ frequencies. 


\section{Comparison with Other UWB Antennas with Band-Notched Function}

In Table 3, we compare our proposed UWB antenna with triple band-notched function with other UWB antennas with band-notched function in the literature. In their designs, some antennas were too large and some antennas did not reject the full WiMAX or WLAN bands. In contrast with other antennas, our proposed antenna has a moderate size and rejects complete WiMAX, WLAN, and X-band satellite applications operating near $8 \mathrm{GHz}$.

Table 3. Comparison between proposed and reported UWB antennas with band-notched function.

\begin{tabular}{|c|c|c|c|}
\hline Reference & Size $(\mathrm{mm})$ & Notched Band (GHz) & Remarks \\
\hline [18] & $70 \times 80$ & $\begin{array}{l}2.4-2.5 \\
4.0-6.0 \\
8.0-8.5\end{array}$ & $\begin{array}{l}\text { Antenna had three notched bands, but size was } \\
\text { too large, and it did not reject WiMAX band }\end{array}$ \\
\hline [19] & $24 \times 35$ & $\begin{array}{l}3.4-4.15 \\
5.3-6.2 \\
6.8-7.7\end{array}$ & $\begin{array}{l}\text { Antenna had three notched bands, but it did } \\
\text { not reject complete WiMAX band and complete } \\
\text { WLAN band }\end{array}$ \\
\hline [20] & $28 \times 30$ & $\begin{array}{r}3.3-3.6 \\
4.5-4.7 \\
5.15-5.35 \\
5.7-5.825\end{array}$ & $\begin{array}{l}\text { Antenna had four notched bands, but it did not } \\
\text { reject the band for X-band satellite applications } \\
\text { operating near } 8 \mathrm{GHz}\end{array}$ \\
\hline [22] & $35 \times 35$ & $\begin{array}{l}2.95-3.72 \\
5.12-6.07 \\
8.04-8.65\end{array}$ & $\begin{array}{c}\text { Antenna had three notched bands, but it had a } \\
\text { larger size }\end{array}$ \\
\hline [23] & $36.6 \times 26$ & $\begin{array}{l}3.36-3.75 \\
5.15-6.0 \\
7.07-8.7\end{array}$ & $\begin{array}{l}\text { Antenna had three notched bands, but it did } \\
\text { not reject complete WiMAX band }\end{array}$ \\
\hline [24] & $30 \times 30$ & $\begin{array}{c}3.3-3.7 \\
5.15-5.825 \\
7.25-7.475\end{array}$ & $\begin{array}{l}\text { Antenna had three notched bands, but it did } \\
\text { not reject the band for } \mathrm{X} \text {-band satellite } \\
\text { applications operating near } 8 \mathrm{GHz}\end{array}$ \\
\hline [25] & $27 \times 30.5$ & $\begin{array}{c}3.36-3.88 \\
4.96-6.23 \\
7.9-8.7\end{array}$ & $\begin{array}{l}\text { Antenna had three notched bands, but it did } \\
\text { not reject complete WiMAX band }\end{array}$ \\
\hline This Work & $35.5 \times 30$ & $\begin{array}{l}2.59-4.01 \\
4.73-6.11 \\
7.68-8.40\end{array}$ & $\begin{array}{c}\text { Antenna had three notched bands, and rejected } \\
\text { complete WiMAX band, complete WLAN band } \\
\text { and the band for X-band satellite applications } \\
\text { operating near } 8 \mathrm{GHz}\end{array}$ \\
\hline
\end{tabular}

\section{Conclusions}

A planar UWB monopole antenna with triple band-notched function at 3.5/5.5/8 GHz is presented in this paper. The low frequency notched band was formed by an arc $\mathrm{H}$-shaped slot on the radiating patch. The other two notched bands were formed by cutting the narrow slots on the ground plane. The presented antenna can avoid the interference from WLAN, WiMAX, and X-band satellite systems. The results of the return loss showed the desired band rejection property. Nearly omnidirectional radiation patterns and desirable gain are also presented to verify the satisfactory performance of the presented antenna.

Author Contributions: J.D. and X.Z. made substantial contributions to the design, analysis, and optimization of the antenna. Additionally, they wrote and revised the paper. G.H. contributed to the experimental measurement and data analysis.

Funding: This work was supported in part by the National Natural Science Foundation of China under Grant No. 61801521, in part by the Natural Science Foundation of Hunan Province under Grant No. 2018JJ2533, in part by the Fundamental Research Funds for the Central Universities of Central South University under Grant No. 2017gczd001 and Grant No. 2018zzts534. 
Conflicts of Interest: The authors declare no conflict of interest.

\section{References}

1. Zhang, J.; Orlik, P.V.; Sahinoglu, Z.; Molisch, A.F.; Kinney, P. UWB systems for wireless sensor networks. Proc. IEEE 2009, 97, 313-331. [CrossRef]

2. Zhu, J.; Li, S.; Feng, B.; Deng, L.; Yin, S. Compact dual-polarized UWB quasi-self-complementary MIMO/diversity antenna with band-rejection capability. IEEE Antennas Wirel. Propag. Lett. 2016, 15, 905-908. [CrossRef]

3. Bilal, M.; Saleem, R.; Abbasi, H.H.; Shafique, M.F.; Brown, A.K. An FSS based non-planar quad element UWB-MIMO antenna system. IEEE Antennas Wirel. Propag. Lett. 2017, 16, 987-990. [CrossRef]

4. Arifin, F.; Saha, P.K. Minimization of path loss for a UWB communication link in a wireless capsule endoscopy system using antenna parameters. In Proceedings of the 2017 IEEE Region 10 Humanitarian Technology Conference (R10-HTC), Dhaka, Bangladesh, 21-23 December 2017.

5. Rahman, M.; NaghshvarianJahromi, M.; Mirjavadi, S.; Hamouda, A. Resonator Based Switching Technique between Ultra Wide Band (UWB) and Single/Dual Continuously Tunable-Notch Behaviors in UWB Radar for Wireless Vital Signs Monitoring. Sensors 2018, 18, 3330. [CrossRef] [PubMed]

6. Donghyun, K. Performance of UWB Wireless Telecommunication Positioning for Disaster Relief Communication Environment Securing. Sustainability 2018, 10, 3857.

7. Thomas, T.; Anh, D.; Khan, W. An Ultra-Wideband Frequency System for Non-Destructive Root Imaging. Sensors 2018, 18, 2438.

8. Rahman, M.; NaghshvarianJahromi, M.; Mirjavadi, S.; Hamouda, A. Bandwidth Enhancement and Frequency Scanning Array Antenna Using Novel UWB Filter Integration Technique for OFDM UWB Radar Applications in Wireless Vital Signs Monitoring. Sensors 2018, 18, 3155. [CrossRef]

9. Kerkhoff, A.; Ling, H. Design of a planar monopole antenna for use with ultra-wideband (UWB) having a band-notched characteristic. In Proceedings of the IEEE Antennas and Propagation Society International Symposium. Digest, Conjunction with: USNC/CNC/URSI North American Radio Sci. Meeting (Cat. No.03CH37450), Columbus, OH, USA, 22-27 June 2003.

10. Schantz, H.G.; Wolenec, G.; Myszka, E.M.I. Frequency notched UWB antenna. In Proceedings of the IEEE Conference on Ultra Wideband Systems and Technologies, Reston, VA, USA, 16-19 November 2003.

11. Kim, Y.; Kwon, D.H. CPW-fed planar ultra-wideband antenna having a frequency band notch function. Electron. Lett. 2004, 40, 403-405. [CrossRef]

12. Huang, C.Y.; Huang, S.A.; Yang, C.F. Band-notched ultra-wideband circular slot antenna with inverted C-shaped parasitic strip. Electron. Lett. 2008, 44, 891-892. [CrossRef]

13. Tang, Z.J.; Wu, X.F.; Zhan, J. Novel compact band-notched UWB antenna using convex-shaped slot patch. Microw. Opt. Technol. Lett. 2015, 57, 201-203. [CrossRef]

14. Chu, Q.X.; Yang, Y.Y. A compact ultrawideband antenna with $3.4 / 5.5 \mathrm{GHz}$ dual band-notched characteristics. IEEE Trans. Antennas Propag. 2008, 56, 3637-3644. [CrossRef]

15. Li, W.T.; Yong, Q.H.; Feng, W.; Shi, X.W. Planar antenna for 3G/bluetooth/WiMAX and UWB applications with dual band-notched characteristics. IEEE Antennas Wirel. Propag. Lett. 2012, 11, 61-64.

16. Mehranpour, M.; Nourinia, J.; Ghobadi, C.; Ojaroudi, M. Dual band-notched square monopole antenna for ultrawideband applications. IEEE Antennas Wirel. Propag. Lett. 2012, 11, 172-175. [CrossRef]

17. Srivastava, G.; Mohan, A. A planar UWB monopole antenna with dual band notched function. Microw. Opt. Technol. Lett. 2015, 57, 99-104. [CrossRef]

18. Yeo, J. Wideband circular slot antenna with tri-band rejection characteristics at 2.45/5.45/8 GHz. Microw. Opt. Technol. Lett. 2010, 50, 1910-1914. [CrossRef]

19. Deng, J.Y.; Yin, Y.Z.; Zhou, S.G.; Liu, Q.Z. Compact ultra-wideband antenna with tri-band notched characteristic. Electron. Lett. 2008, 44, 1231-1233. [CrossRef]

20. Rahman, M.; Ko, D.S.; Park, J.D. A compact multiple notched ultra-wide band antenna with an analysis of the CSRR-TO-CSRR coupling for portable UWB applications. Sensors 2017, 17, 2174. [CrossRef]

21. Rahman, M.; Park, J.D. The Smallest Form Factor UWB Antenna with Quintuple Rejection Bands for IoT Applications Utilizing RSRR and RCSRR. Sensors 2018, 18, 911. [CrossRef] 
22. Sarkar, D.; Srivastava, K.V.; Saurav, K. A Compact Microstrip-Fed Triple Band-Notched UWB Monopole Antenna. IEEE Antennas Wirel. Propag. Lett. 2014, 13, 396-399. [CrossRef]

23. Wang, J.; Wang, Z.; Yin, Y.; Liu, X. UWB Monopole Antenna with Triple Band-Notched Characteristic Based on a Pair of Novel Resonators. Prog. Electromagn. Res. C 2014, 49, 1-10. [CrossRef]

24. Mohammed, H.J.; Abdullah, A.S.; Ali, R.S.; Abd-Alhameed, R.A.; Abdulraheem, Y.I.; Noras, J.M. Design of a uniplanar printed triple band-rejected ultra-wideband antenna using particle swarm optimisation and the firefly algorithm. IET Microw. Antennas Propag. 2016, 10, 31-37. [CrossRef]

25. Cai, Y.Z.; Yang, H.C.; Cai, L.Y. Wideband Monopole Antenna with Three Band-Notched Characteristics. IEEE Antennas Wirel. Propag. Lett. 2014, 13, 607-610.

26. Rahman, M.; Khan, W.T.; Imran, M. Penta-notched UWB antenna with sharp frequency edge selectivity using combination of SRR, CSRR, and DGS. AEU-Int. J. Electron. Commun. 2018, 93, 116-122. [CrossRef]

2018 by the authors. Licensee MDPI, Basel, Switzerland. This article is an open access article distributed under the terms and conditions of the Creative Commons Attribution (CC BY) license (http://creativecommons.org/licenses/by/4.0/). 